Volume 2, Issue 2, April-June 2017, Pages: 194, DOI: http://dx.doi.org/10.19082/ah194

\title{
GASTRIC, ESOPHAGEAL, AND COLON CANCERS BIOBANK IN NORTHEAST IRAN
}

\author{
Ladan Goshayeshi ${ }^{1,3, *}$, Abbas Esmaieilzadeh ${ }^{2,3}$, Kambiz Akhavan Rezayat ${ }^{2,3}$, Hooman Moosanen Mozaffari $^{2,3}$,
} Omid Ghanaee ${ }^{2,3}$, Benyamin Hoseini ${ }^{4}$

1: Surgical Oncology Research Center, Mashhad university of Medical Sciences, Mashhad, Iran.

2: Gastroenterology and Hepatology Research Center, Mashhad University of Medical Sciences, Mashhad, Iran.

3: Department of Gastroenterology and Hepatology, Faculty of Medicine, Mashhad University of Medical Sciences, Mashhad, Iran.

4: Student Research Committee, Department of Medical Informatics, Faculty of Medicine, Mashhad University of Medical Sciences, Mashhad, Iran.

\section{Correspondence:}

Ladan Goshayeshi, Tel: +989155109704, Fax: +98800598818, E-mail: goshayeshil@mums.ac.ir

\section{TYPE OF ARTICLE: CONFERENCE ABSTRACT}

\begin{abstract}
Introduction: Gastric, esophageal and colon cancers are prevalent in Iran. Human bio specimens are increasingly utilized as materials in cancer research. Modern, molecular biomedicine is driving a growing demand for extensively annotated tissue bank specimens. These biological samples provide valuable information on the prevalence of germline mutations, epigenetic modifications or interaction between genes and proteins associated with the development of cancers. The study aimed to develop a biobank of gastric, esophageal, and colon cancers in Mashhad, Iran.

Methods: Repository of blood and fresh cancer tissues have been stored in a biobank in the endoscopy unit of imam Reza hospital since 1395 (2016). Standard questionnaires have been developed to collect demographics, ethnicity, personal history of cancer, as well as the patient's tumor tissue characteristics. Pathology reports were added to registered demographic patient data.

Results: Blood and fresh tissue of 59 colon cancer, 63 gastric cancer, and 27 esophageal cancer specimens were saved in the data biobank.

Conclusion: Bio specimens will be a good source for further studies to investigate genetic and epigenetic causes in esophageal, gastric and colon cancers and assess valuable serum biomarkers for these common cancers in Iran. It will also help specialists to use new treatments for related patients and will help policy makers to apply appropriate and preventable policies to decrease cancer incidence.
\end{abstract}

KEYWORDS: Colon, esophageal, Gastric, Cancer, Registry, Biobank, Mashhad

\footnotetext{
Abstracts of First National Congress of Medical Informatics, Mashhad, Iran, February 2017

(C) 2017 The Authors. This is an open access article under the terms of the Creative Commons Attribution-NonCommercialNoDerivs License, which permits use and distribution in any medium, provided the original work is properly cited, the use is non-commercial and no modifications or adaptations are made.
} 